\section{¿REACCIÓN INSTITUCIONAL O AVANZADA DICTATORIAL? LAS TENSIONES ENTRE EL CONGRESO Y EL EJECUTIVO A COMIENZOS DEL SIGLO XX}

INSTITUTIONAL REACTION OR DICTATORIAL PUSH?

TENSIONS BETWEEN CONGRESS AND THE EXECUTIVE AT THE BEGINNING OF THE 2OTH CENTURY

\section{MARTÍN CASTRO .}

Investigador Independiente del CONICET con sede en Instituto de Historia Argentina y Americana «Dr. Emilio Ravignani» de la Universidad de Buenos Aires.

E-mail: martincastromdp@yahoo.com.ar

\section{Resumen}

La clausura de las sesiones del Congreso argentino dispuesta por José Figueroa Alcorta en 1908 dejó expuestas la fragilidad de los alineamientos políticos y las dificultades del gobierno para consolidar una coalición parlamentaria estable. Este artículo explora el rol del Congreso en el ordenamiento político argentino a partir del análisis del debate sobre la legitimidad del llamado "golpe de Estado». Se analiza el carácter disruptivo de la medida introducida por el gobierno de Figueroa Alcorta y se procura avanzar en la comprensión de las relaciones entre el Poder Ejecutivo Nacional y el Congreso durante el «orden conservador» a la luz de la comparación del conflicto de 1908 con las tensiones experimentadas en la década de 1890 relativas a la solidez de los ejecutivos, la legitimidad de los representantes y el alcance de la división de poderes.

\section{Registro bibliográfico}

CASTRO, MARTÍN «¿Reacción institucional o avanzada dictatorial? Las tensiones entre el congreso y el ejecutivo a comienzos del siglo XX», en: ESTUDIOS SOCIALES, revista universitaria semestral, año XXIX, n 56, Santa Fe, Argentina, Universidad Nacional del Litoral, enero-junio, 2019, pp. 37-60.

\section{Abstract}

José Figueroa Alcorta's decision to close the Congress sessions exposed the fragility of political alignments and the difficulties that the government had in building a stable parliamentary coalition. To explore the role that Congress played in the Argentine political system this article analyses the debates about the legitimacy of the so-called "coup d'état». It examines the disruptive nature of Figueroa Alcorta's decision and attempts to contribute to the understanding of the relationships between the National Executive and Congress during the "Conservative Order» by comparing the 1908 crisis with political crises in the 1890s. Particular attention is paid to the power of the Executive, the legitimacy of representatives and the nature of the division of powers.

\section{Descriptores · Describers}

parlamento / golpe / prensa / ejecutivo / historia politica Parliament / Coup / Newspapers / Executive Power / Political History

Recibido: 27 / 08/2018 Aprobado: 08/11/2018 
La renovación de la historia política ha tenido un impacto tardío en el campo de los estudios parlamentarios ${ }^{1}$. Hasta hace algunos años la historiografía política en la Argentina había dedicado una atención escasa y tangencial al rol de las asambleas legislativas en la configuración y la dinámica de la vida política de finales del siglo XIX y comienzos del siglo XX (CANTÓN, I966; MOLINELLI, 199I). En relación con el período que Natalio Botana denominó «orden conservador» (BOTANA, [1977] 20I2), una prolífica literatura nos ha brindado una mirada ciertamente más compleja del funcionamiento de la política del periodo, lejos de aquellas interpretaciones que arriesgaban un dominio absoluto del Partido Autonomista Nacional (en adelante PAN) (SABATO, 2OI4; MÍGUEZ, 2OI2). Ese crecimiento historiográfico, sin embargo, solo alcanzó de manera despareja a los trabajos dedicados a indagar sobre el lugar del Congreso Nacional en el entramado político. Es posible que ello se debiera al carácter presidencialista de la Constitución Nacional de I853 y a la atención especial dirigida por los investigadores hacia la influencia del Ejecutivo nacional en la construcción de las instituciones estatales. De manera similar, como sugirió Paula Alonso hace casi dos décadas, que los historiadores políticos concentraran sus esfuerzos en el rol del PAN también favorecía interpretaciones que entendían a las Cámaras como meras expresiones de decisiones que se tomaban en otras esferas (ALONSO, 2000).

En los últimos años se ha experimentado un renacido interés en las investigaciones sobre la institución parlamentaria y su relevancia política a finales del siglo XIX y comienzos del siglo XX (CASTRO, 2OI7; CUCHI Y ROMERO, 2OI7). Esa renovada atención -que se observa, de manera más amplia, en los estudios latinoamericanos-permite recuperar el rol jugado por los legisladores en la definición de las agendas parlamentarias, en el diseño de los mecanismos de limitación al poder del Ejecutivo y en la constitución de las legislaturas como foros de deliberación (POSADA CARBÓ, 20I7). Este artículo reconoce estas preocupaciones y procura contribuir a la indagación de la "culturas parlamentarias» (IHALAINEN, 20I8) y de las formas concretas de la relación entre los poderes Ejecutivo y Legislativo a partir del estudio del denominado «golpe de Estado» de 1908. La exploración de la crisis política que desembocó en el cierre del Congreso en enero de 1908 constituye, además, una vía de acceso a las maneras en que la prensa y actores sociales y políticos interpretaban al rol del Congreso en

1] Una versión preliminar de este trabajo fue presentada en las XVI Jornadas Interescuelas/Departamentos de Historia, Mar del Plata, 9-11 de agosto de 2017. Agradezco los comentarios de Hilda Sabato a una versión previa de este texto. 
el proceso político. Este trabajo se abre con una breve descripción de los procedimientos parlamentarios, el rol de las cámaras en la ingeniería constitucional y del proceso de fragmentación de la elite política en el cambio de siglo. Se argumenta que la profundización de las vinculaciones inestables entre las redes de amigos políticos tendría su correlato en la dificultad en constituir coaliciones parlamentarias capaces de consensuar agendas, moderar las disputas -internas y con el Ejecutivo- e impedir una parálisis legislativa. A finales del siglo XIx, los debates parlamentarios que implicaban una reflexión sobre la división de poderes y el activo involucramiento de las Cámaras en coyunturas críticas (1890 y 1895) mostraron un Congreso que procuraba (y en ocasiones obtenía) una limitación a la expansión del poder presidencial. A la luz del debate generado entre la dirigencia política, en la prensa y en las calles en torno a la decisión de José Figueroa Alcorta de clausurar las sesiones extraordinarias del Congreso (descripta por sus críticos como una avanzada «dictatorial»), este trabajo sugiere la conveniencia de revisar apreciaciones apresuradas sobre el poder avasallante que el presidencialismo habría demostrado sobre la institución parlamentaria a finales del «orden conservador». La fortaleza de los movimientos de opinión que dirigieron sus peticiones hacia el Parlamento en los meses subsiguientes y la rapidez con que se desvanecieron los rumores sobre una posible disolución del Congreso también advierten sobre la necesidad de revisar la hipótesis de un presidencialismo con escasos límites. Finalmente, aquí se argumenta que la clausura del Congreso y los meses que siguieron hasta la apertura del año parlamentario en 1908 constituyeron un escenario favorable para que dos problemáticas que constituían núcleos relevantes en el debate intelectual y entre las dirigencias políticas a principios del siglo xx confluyeran: el déficit de legitimidad -lo que conducía a perseguir la ampliación de las bases del régimen político y mecanismos electorales transparentes- $y$ los límites a la arbitrariedad del poder presidencial que se perseguían a partir de una reformulación del gobierno representativo, cuestión esta última que sería central en la reflexión posterior de la Revista Argentina de Ciencias Políticas (ROLDÁN, 2006: 58)

\section{COALICIONES POLÍTICAS Y PRÁCTICAS PARLAMENTARIAS}

El proyecto constitucional finalmente concretado entre 1853 y I860 adoptó la forma representativa, republicana y federal en un modelo que expresaba con nitidez una inclinación hacia el predominio del Poder Ejecutivo. La definición 
de un modelo de federalismo centralizado con tonos presidencialistas claros (evidenciados en el mecanismo de la intervención federal para garantizar la forma republicana de gobierno, el nombramiento del gabinete de ministros sin necesidad de la aprobación parlamentaria o la declaración del estado de sitio durante el receso parlamentario) (NEGRETTO Y AGUILAR-RIVERA, 2000) no impidió, sin embargo, la persistencia de los debates en la esfera pública y en el Congreso en relación a las notas definitorias de la división de poderes. Ejemplo de ello fueron los intentos por regular la práctica de la intervención federal y las dificultades en alcanzar acuerdos de largo plazo sobre su implementación o sobre la naturaleza del gobierno federal. Luego de I880, y a pesar de la relevancia del PAN y de su influencia en la política provincial y parlamentaria, el Congreso no sólo fue un foro de debate clave en la discusión doctrinaria sobre el sistema republicano sino que también fue capaz de bloquear intentos del Ejecutivo de llevar adelante intervenciones federales sin aprobación parlamentaria o de recurrir a las interpelaciones a los ministros del Ejecutivo con el objeto de limitar el dominio presidencial. (CUCCHI Y ROMERO, 2OI7)

En i88o la derrota en el campo de batalla de las fuerzas porteñas ante los ejércitos del gobierno central significó un paso decisivo -aunque no completo ni definitivo, como se ha demostrado recientemente (ALONSO, 2OIO; GERCHUNOFF, ROCCHI Y ROSSI, 2008) - en la consolidación del Estado nacional y en la subordinación de la dirigencia política porteña (sabato, 2008). Sin duda, la incidencia de las transformaciones incorporadas por los combates de I880 en la concreción de los diferentes órdenes políticos provinciales (y en su articulación con el nivel nacional) estuvo lejos de ser homogénea (BRAGONI y MíGUEZ, 20IO), si bien la década de I880 contribuyó a dotar de sus trazos fundamentales a una configuración de poder (el PAN) que actuó como reguladora de las tensiones y conflictos entre las variadas dirigencias provinciales. Lejos de contar con estructuras partidarias permanentes e institucionalizadas, el PAN facilitó las vinculaciones entre los partidos provinciales (que se reconocían parte de aquella coalición) y las instituciones estatales y reconoció un margen de acción considerable a las ligas de gobernadores en las luchas por la sucesión presidencial en las décadas de I880 y I890 (AlONSO, 20IO). Con el cambio de siglo, las coaliciones políticas del novecientos experimentaron dificultades mayores para mantener una cierta cohesión y los riesgos de fragmentación del antiguo PAN estimularon el debate sobre los mecanismos del gobierno representativo y la viabilidad de introducir cambios significativos en la legislación electoral (CASTRO, 20I2). En este nuevo contexto, publicistas y prensa interesados en la discusión de la 
legitimidad electoral de los parlamentarios y las modalidades concretas del modelo federal posaron su ojo crítico sobre las habituales negociaciones entre el presidente, los legisladores prominentes y los gobernadores en torno a la conformación de los apoyos parlamentarios y cuestionaron la correlación de fuerza entre la «situaciones provinciales» y la definición de las agendas legislativas (CASTRO, 20I7).

No sorprende, entonces, que en la primera década del siglo fueran recurrentes las críticas reformistas dirigidas al origen electoral de los representantes, cuestionando los consensos internos de las elites provinciales y los acuerdos alcanzados con el Ejecutivo nacional. Sin embargo, como se argumentará más adelante, no por ello el escenario parlamentario estuvo ajeno a las expresiones de la opinión pública o los debates legislativos carecieron de significación en la vida política del período. Por el contrario, como revelan las crónicas de la prensa, el inicio del año parlamentario era esperado con expectativa cada $\mathrm{I}^{\circ}$ de mayo y la ceremonia era rodeada de todo el boato que el Estado argentino era capaz de producir. La inauguración del nuevo edificio del Parlamento en 1906, como parte de un plan más amplio que incorporaba ejemplos de arquitectura monumental y republicana, fortalecía el eje cívico constituido entre la Casa de Gobierno y el edificio del Congreso (CASTRO, 2OI7; SCHMIDT, 2OI2). De acuerdo a la Constitución Nacional las sesiones ordinarias de ambas cámaras del Congreso se extendían entre el I I de mayo y el 30 de setiembre de cada año pero podían ser ampliadas extraordinariamente por el presidente o prorrogadas sus sesiones por resolución de la Cámara. Cada Cámara era a su vez juez de las elecciones, títulos y derechos de sus miembros y se asignaba su propio reglamento de funcionamiento. Los reglamentos internos establecían una serie de severas disposiciones para compeler a la asistencia de los legisladores a las sesiones, si bien su cumplimiento en la práctica estaba lejos de ser generalizado (REGLAMENTO DE LA CÁMARA DE SENADORES DE LA NACIÓN, I9O7; REGLAMENTO DE LA CÁMARA DE DIPUTADOS DE LA NACIÓN ARGENTINA, I909).

La prensa porteńa y de las provincias solía brindar una profusa información sobre los debates e incidentes ocurridos durante la discusión de los proyectos o de las interpelaciones a los ministros del Poder Ejecutivo. Incluso a comienzos de la década de 1880 se editaría un periódico dedicado exclusivamente a los debates parlamentarios ${ }^{2}$. Pero, además, la relevancia de los debates parlamentarios se percibe con claridad en las manifestaciones en las calles que tenían por destinatario

2] «El Parlamento», La Nación (LN), 03/10/1880. 
al Congreso (rojkind, 2006; CASTRo, 2009). Si este desarrollo de meetings se encontraba en sintonía con la tradicional cultura de la movilización advertida en la ciudad de Buenos Aires, también expresaba la decisión de un sector de la sociedad que reconocía la relevancia del ámbito parlamentario y la necesidad de ejercer presión ante la posibilidad de un voto desfavorable. En este sentido, la organización de sectores de la sociedad civil o de ligas políticas dirigida a ejercer una influencia sobre los parlamentarios expresaba la creencia de que el Congreso contaba con márgenes de autonomía que le permitía acceder a tomas de posición diferenciadas de la agenda del Ejecutivo nacional.

Otras acciones también iban encaminadas en la misma dirección como la asistencia de manifestantes a las sesiones parlamentarias de debate, si bien esta práctica contaba con abundantes antecedentes en el siglo XIX (SABATO, 2008: I24). Aun cuando es difícil concluir a partir de los ejemplos mencionados anteriormente que el Congreso fuera interpretado por estos diversos actores como «representativo» (MACKInNon, 20I7) (como veremos, una de las cuestiones debatidas en torno al «golpe de Estado» de 1908 sería la representatividad del ámbito parlamentario), es indudable que el poder legislativo era identificado como un engranaje relevante del ordenamiento institucional sobre el cual merecían dirigirse acciones tendientes a influenciar tomas de decisión. En este sentido puede interpretarse la presencia de militantes de Centros Socialistas y grupos de mujeres en las sesiones de Diputados destinadas al debate del proyecto del representante socialista Alfredo Palacios sobre el trabajo de mujeres y niños a lo largo de 1907 o la asistencia de trabajadores en el recinto ansiosos de escuchar las respuestas de los ministros del Ejecutivo luego de la represión de los obreros de Ingeniero White ${ }^{3}$.

El ámbito parlamentario quedaba, sin embargo, frecuentemente expuesto a las críticas directas de la prensa nacional, una situación que lejos de ser excepcional también era compartida por otros escenarios nacionales (como el español o el italiano) expuestos a la crítica reformista, regeneracionista o directamente antiparlamentaria (MORENO LUZÓN, 2OI5; RAGAZZONI Y URBINATI, 20I8). La Constitución y los reglamentos de las Cámaras reconocían la importancia de dar a publicidad no sólo los proyectos convertidos en ley sino también el contenido de los debates parlamentarios. A partir de i88o, los debates sobre la construcción de un nuevo edificio para el Congreso habían dejado expuesta esta problemática (CASTRO,

3] Diario de Sesiones de la Cámara de Diputados (DSCD), 31/07/1907. 
20I7). La mayoría de las expresiones de la prensa nacional asignaba secciones en sus páginas a la cobertura de las noticias parlamentarias y destinaban reporters de manera permanente en el edificio del Congreso. Sin embargo, los representantes de los diarios porteños demostraban reflejos rápidos para evitar ser absorbidos por las oficinas de prensa parlamentarias y apuntarían críticamente sobre la escasa actividad del Congreso, resultado en parte de las tácticas de obstrucción desarrolladas durante los primeros ańos de la presidencia de Figueroa Alcorta. Es en este sentido que puede interpretarse, por ejemplo, la campaña del diario La Nación en contra de lo que definía como la «holganza parlamentaria» expresada en la escasa asistencia de los diputados y senadores al recinto acompańada de una escasa productividad de las Cámaras que se veían absorbidas en conflictos interminables en torno a elecciones y aprobación de diplomas parlamentarios, negociaciones en torno al presupuesto y poco más ${ }^{4}$. Era claro, por otra parte, que aquella «holganza» respondía a la decisión de un número considerable de representantes de trabar aquellas sesiones que podían tener consecuencias políticas de relevancia para el gobierno nacional. Si en problemáticas que escapaban a los alineamientos facciosos las votaciones podían responder al «juicio espontáneo» de los legisladores ${ }^{5}$, los debates sobre la necesidad de una intervención federal o la sanción del presupuesto general de gastos del gobierno nacional daban lugar a farragosas negociaciones y obstruccionismo por parte del bloque parlamentario opositor.

\section{OBSTRUCCIONISMO PARLAMENTARIO Y EL «GOLPE DE ESTADO» DE 1908}

La ruptura de la tradicional alianza entre Julio A. Roca y Carlos Pellegrini, la realización de una Convención de Notables en 1903 -que tuvo como resultado la selección de un candidato presidencial ajeno al PAN-, y la conformación de un partido pellegrinista que procuraba levantar banderas de reforma política introdujeron profundas tensiones en la dinámica interna del ordenamiento conservador. A regañadientes los gobernadores y principales amigos políticos de Roca habían mantenido su apoyo a la candidatura de Manuel Quintana aunque no sin mani-

4] «La prensa y el parlamento», LN, 21/07/1907; «La labor parlamentaria. Prácticas viciosas», LN, 23/08/1907.

5] «El proyecto sobre los territorios», $L N, 23 / 08 / 1907$. 
festar preocupación frente a la continuidad de las «situaciones provinciales». Roca y sus aliados perseguían, mientras tanto, la consolidación de sus posiciones en las provincias y en el Senado ${ }^{6}$. Con la elección consumada, el escenario se encontraba entonces delimitado por un Ejecutivo debilitado por las características de su elección y un Congreso en el cual los grupos parlamentarios mantenían una afinidad con la tradición política del PAN (y parcialmente con el liderazgo de Roca) pero que adoptarían a las sesiones del Congreso como un laboratorio de construcción de coaliciones y posibles alianzas políticas ${ }^{7}$. Cuestiones de supervivencia influyeron, además, sobre las estrategias de los grupos dirigentes provinciales en sus relaciones con el gobierno central y contribuyeron a dar forma a un terreno propicio para el surgimiento de nuevos pactos de adhesión regional, con los políticos bonaerenses (Marcelino Ugarte) a la cabeza (CASTRO, 2OI2).

El corrimiento de Pellegrini hacia la oposición también había brindado nuevos elementos al debate sobre la emergencia de proyectos partidarios alternativos y dado lugar a pronósticos de finalización de un régimen político, a los cuales la revolución radical de 1905 no había dejado de contribuir. El ascenso de José Figueroa Alcorta a la presidencia en 1906 (luego de la muerte de Quintana) se da, por lo tanto, en momentos de crisis del PAN y de surgimiento de coaliciones antirroquistas que recurren a la bandera de la reforma política, en parte con la intención de canalizar la movilización de los sectores medios porteños. Para el gobierno de Figueroa Alcorta este escenario condicionaría significativamente su voluntad de introducir una reforma electoral, voluntad que sería puesta en duda de manera constante por la prensa reformista de Buenos Aires temerosa de presenciar el ascenso de una nueva máquina política. En un contexto de fragmentación política las tensiones entre el gobierno central y las dirigencias provinciales crecieron constantemente como se advierte en el número de las intervenciones federales y en los constantes conflictos con el Congreso (sommariva, I93I: 332 ).

Estos conflictos podían asumir la forma de desafíos abiertos (aprobación de diplomas de parlamentarios contrarios al gobierno nacional o rechazo a los proyectos de intervención federal) pero también podían expresarse en una decidida actitud de desidia que sería advertida por la prensa cercana al gobierno federal.

6] J.V. de Olmos a J.A. Roca, 28/09/1904, Archivo General de la Nación (AGN), Fondo Julio A. Roca (FJAR), Legajo 1332.

7] Discurso de Mariano de Vedia, DSCD, 1905, t. I, p. 865. 
Así, la apatía del Congreso demostrada en el tratamiento del proyecto del Poder Ejecutivo dedicado a una reforma de la ley electoral expresaba el rechazo de un número de parlamentarios a la política de intervención del gobierno central en la vida política provincial ${ }^{8}$. Los esfuerzos del gobierno nacional por constituir un bloque parlamentario propio que sostuviera sus iniciativas encontraban algunos éxitos parciales (por caso, en la elección de las autoridades de la Cámara de Diputados) si bien pronto se advirtieron rechazos entre los oficialismos provinciales y «un movimiento general de concentración en las filas del Partido Nacional»?. Más allá de la correspondencia entre los políticos provinciales - que deja entrever estos movimientos- algunos publicistas de la época, entre ellos Rodolfo Rivarola no dejaron de señalar las dimensiones adquiridas por el conflicto entre el Congreso y el Poder Ejecutivo, al extremo de identificarlo como una de las controversias centrales de la vida política de comienzos de siglo (RIVArola, I908: 450).

El enfrentamiento creciente entre el gobierno de Figueroa Alcorta y un Congreso que dilataba la sanción del presupuesto nacional para el año 1908, sumado a las dificultades del gobierno central para asegurar una mayoría propia en el Parlamento, dio el contexto a la decisión del Ejecutivo nacional de clausurar las sesiones extraordinarias del Congreso en enero de 1908 y ordenar la ocupación del edificio parlamentario. Quienes simpatizaban con el presidente argumentaron, entonces, la «razón de Estado» por encima de las acusaciones de inconstitucionalidad. El cierre del Congreso, rechazado en fuertes términos por los legisladores opositores, encontró expresiones de ambigüedad de parte de los gobiernos provinciales que cuidaban sus movimientos futuros (CASTRO, 2012: 222-225).

La estrategia parlamentaria de las diferentes facciones provinciales del PAN y del ugartismo había asumido en los meses previos una característica ante todo defensiva. La oposición hacia la llamada «política de reacción institucional» de Figueroa Alcorta que proponía introducir la transparencia en las prácticas electorales y transformar los equilibrios de poder provinciales encontró contornos manifiestos en el bloqueo de decisiones clave que el Congreso asumiría en esos meses finales del año, entre ellas la intervención federal a la provincia de Corrientes y, crucialmente, la sanción del presupuesto para el año 1908. En un principio los parlamentarios no

8] $L N, 26 / 7 / 1906$.

9] F. Yofre a J.A. Roca, 29/9/1906, AGN, Archivo Felipe Yofre, Legajo 2346. 
buscaban la desestabilización del gobierno sino más bien evitar que la aceptación que Figueroa Alcorta había hecho del apoyo de la Coalición Popular con base en la ciudad y en la provincia de Buenos Aires, la condujera al rechazo del tradicional sustento del Partido Nacional y de los gobernadores provinciales.

Cierta fluidez en los alineamientos parlamentarios y la decisión de parte del Ejecutivo (no excesivamente notoria a lo largo de 1907) de construir una mayoría en el Congreso que le permitiera horadar la antigua influencia roquista lo acercaba a alianzas circunstanciales estructuradas en torno a dosis considerables de pragmatismo político, como se advierte en las negociaciones con los diputados bonaerenses. Como iba a señalar perspicazmente el diario La Nación, entre los apoyos de los diputados bonaerenses que respondían a Marcelino Ugarte en la Cámara de Diputados y el bloque de diputados presidenciales no existía ni «solidaridad de pensamiento» ni «analogía de propósitos» ${ }^{10}$. Se parecía demasiado a un matrimonio por conveniencia en el cual Ugarte esperaba hacerse del apoyo del presidente para las todavía lejanas elecciones presidenciales de I9ıo a cambio de la concurrencia de los votos bonaerense en socorro de un urgido gobierno nacional.

Frente al nuevo escenario abierto con la clausura de las sesiones extraordinarias por parte del Ejecutivo nacional y la ocupación del edificio del Congreso, los círculos parlamentarios y grupos políticos reaccionaron lentamente. Este nuevo territorio da lugar a una serie de rumores que van desde el cierre definitivo del Congreso (seguido por un amplio programa de intervenciones federales en las provincias) a voces que anuncian levantamientos en las provincias y el establecimiento de una asamblea parlamentaria sediciosa en la provincia de Buenos Aires. Sin duda, el decreto de clausura de las sesiones extraordinarias del Congreso del 25 de enero expresaba la voluntad del presidente de introducir cambios en el equilibrio de poder de los grupos parlamentarios, enfrentando las dilaciones del ugartismo y, de manera inevitable, disciplinando al Congreso. De acuerdo con el decreto, los retrasos en tratar los asuntos propuestos para las sesiones extraordinarias (fundamentalmente el acuerdo del Senado para el nombramiento del intendente municipal de Buenos Aires y del presidente del Consejo Nacional de Educación, pero sobre todo la sanción del presupuesto) no sólo significaba perseguir una disminución de la «autoridad moral» del Ejecutivo sino plantar «el germen de la

10] «En el vacío», $L N, 19 / 01 / 1908$. 
anarquía y de la guerra civil ${ }^{11}$. Acompañado de la firma del presidente y de sus ministros, el decreto establecía la vigencia del presupuesto sancionado para el año I907 y declaraba clausuradas las sesiones extraordinarias del Congreso y retirados los asuntos sometidos a su deliberación.

La ocupación del edificio del Congreso no encontró, sin embargo, apoyo unánime entre el frágil entramado de fuerzas que habían sostenido a Figueroa Alcorta en el poder desde comienzos de 1906. Entre los autonomistas, una figura de peso como Juan Balestra (quien desempeñaría un rol clave en la coalición que llevaría a Roque Sáenz Peña al poder dos años más tarde) expresó su rechazo más profundo a la medida advirtiendo, en su discurso parlamentario de mayo de 1908, sobre los riesgos de una completa unanimidad legislativa ${ }^{12}$. Sin embargo, pese a las divergencias que se encontraban entre los autonomistas ante esta decisión abrupta del presidente, quien se dibujaba a la distancia como el político autonomista capaz de reclamar el bastón de mando dejado por Carlos Pellegrini, no dejaba dudas sobre las dimensiones del triunfo del Ejecutivo sobre la oposición parlamentaria. Roque Sáenz Peña, en efecto, se encontró entre los más entusiastas sostenedores de la validez de la decisión presidencial ${ }^{13}$.

Esa situación de excepcionalidad a la cual el decreto de enero se remitía-aunque permaneciendo convenientemente en el territorio de la ambigüedad, es decir una probable «guerra civil» y el paso a la anarquía tan temida- no tiene su correlato, sin embargo, en acciones acordes con esta retórica ni con las expectativas abiertas con el "golpe de Estado». En definitiva, éste se mantiene en el terreno de las apariencias: el gobierno se cuida bien de no ofrecer más argumentos a aquellos que sostienen la inconstitucionalidad de la medida y elige el camino más tradicional de la negociación (desde una posición de fuerza) con los gobernadores reticentes para definir listas de candidatos a la Cámara de Diputados que fueran cercanas al paladar presidencial. La frustración frente a la estrategia perseguida por el gobierno nacional se advierte, por ejemplo, en Emilio Lamarca, dirigente católico cercano a Roque Sáenz Peña que señalaba desilusionado, poco más de un año después, el excepcional acontecimiento. Afirmaba que habiendo podido el presidente realizar

11] Tribuna (T), 25/01/1908.

12] Ésta daba lugar a «barcos cuyas calderas no tienen válvulas de seguridad», $L N, 08 / 05 / 1908$.

13] R. Sáenz Peña a E. Ramos Mexía, 29/05/1908, Academia Nacional de la Historia, Archivo Roque Sáenz Peña (AFRSP), Legajo 141. 
un "golpe de Estado» se había contentado con llevar adelante unas elecciones buscando «capital político» ${ }^{14}$. La expresión "golpe de Estado» rápidamente estuvo en la boca y en la pluma de periodistas y políticos. Para el Buenos Aires Herald, favorable a la medida, era justamente el carácter constitucional de esta última el que impedía apelar al concepto de "golpe» ${ }^{15}$. Los amigos políticos de Roca, por el contrario, incorporaron sin hesitar el uso del término para referirse a una medida que interpretaban como parte de un plan más amplio del presidente para asegurase una Cámara de diputados favorable ${ }^{16}$. Para periodistas como Agustín de Vedia (antiguo editor de Tribuna, que a comienzos de siglo había sido un diario estrechamente ligado a Roca) el «golpe» significaba el ingreso en un territorio desconocido, una "gran subversión» que podía poner en riesgo la «organización constitucional de la República ${ }^{17}$. En esto coincidía el mismo Julio A. Roca quien veía en la medida tomada por el «vicepresidente» un retroceso hacia prácticas políticas similares a las de "Rusia y de los pueblos del Asia» ${ }^{18}$.

Para la prensa que apoyaba la «política de reacción institucional» de Figueroa Alcorta, la respuesta de la opinión pública había demostrado aspectos menos ambiguos y más favorables. De acuerdo con Tribuna, la clausura del Congreso había contado con el apoyo de la opinión desde un comienzo. Ante las noticias del cierre del Parlamento, la Bolsa y la "gente de los negocios» se encontrarían entre los primeros en apoyar la medida. Grupos de curiosos se concentraron frente a las oficinas del Telégrafo Nacional y entre la multitud circularon comentarios irónicos sobre los «petizos» $\mathrm{y}$ «furiosos» miembros del Parlamento. Para el diario oficialista nunca había estado «mejor computada la voluntad popular que en esta clausura del poder legislativo, en trance de imposiciones intolerables ${ }^{19}$. A su llegada al despacho presidencial la tarde del cierre, Figueroa Alcorta recibió a políticos y miembros de la banca y el comercio que se acercaron a felicitarlo por la medida y se habilitó en la secretaría un libro para que quedaran consignadas las firmas de la numerosa concurrencia.

14] Emilio Lamarca a Roque Sáenz Peña, 09/07/1909, AFRSP, caja 21.

15] Buenos Aires Herald, 26/01/1908, AGN, Fondo José Figueroa Alcorta (FJFA), legajo 13.

16] Ángel Avalos a Julio A. Roca, 22/03/1908, AGN, FJAR, 3104, legajo 3.

17] A. de Vedia a Julio A. Roca, 25/01/1908, AGN, FJAR, legajo 1324, 96.

18] Julio A. Roca a Lucas Córdoba, 30/06/1908, AGN, FJAR legajo 1344.

19] $T, 25 / 1 / 1908$. 
El edificio del Congreso permaneció custodiado por un destacamento de bomberos ( 150 hombres), armados con mausers. Fueron horas de fuertes especulaciones y rumores, entre ellos un supuesto plan de Marcelino Ugarte de trasladarse a La Plata, decidir la separación de la provincia del resto de la «confederación argentina» para luego movilizar a las tropas bonaerenses (unos seis mil hombres) contra el gobierno nacional. Los acercamientos entre ugartistas y roquistas tenían límites ciertos en antiguos rencores también parlamentarios (el descabezamiento de las autoridades de las Cámaras favorables al roquismo en 1907) y las discusiones giraron (en la prensa y en los círculos políticos) sobre la constitucionalidad del decreto y los probables alineamientos de los gobiernos provinciales. Así como en las provincias dónde se registraron manifestaciones públicas ante la decisión del Ejecutivo, en la ciudad de Buenos Aires entre el 28 y 29 de enero se congregaron grupos de manifestantes (cinco mil, según Tribuna, en los alrededores de la Casa de Gobierno y en las cercanías del domicilio de Figueroa Alcorta) en apoyo a la decisión del presidente ${ }^{20}$. Los parlamentarios se reunieron ese mismo 28 (luego del acuerdo de gabinete que refrendaba la decisión presidencial) en los hoteles Paris e Imperial, tratando de verificar la densidad de los apoyos políticos e iniciando negociaciones cruzadas entre ugartistas, republicanos y roquistas ${ }^{21}$. Para Tribuna, la opinión pública se demostraba favorable a la decisión presidencial cansada del obstruccionismo parlamentario y de «señores del congreso que se tragaban I5Oo al mes sin hacer nada». De las discusiones de los legisladores opositores al gobierno de Figueroa Alcorta (roquistas y ugartistas) emergieron eventualmente dos manifiestos contrarios al cierre y en defensa de la autonomía del espacio parlamentario ${ }^{22}$.

Luego de la clausura de las sesiones extraordinarias, los gobernadores se mantuvieron en una zona de indefinición en la que no faltaron, como mencionamos, los rumores de revueltas contra el gobierno o de acercamientos antes impensables. De una rápida exploración de la correspondencia de Figueroa Alcorta con amigos políticos y un conjunto extenso de asociaciones, movimientos locales y estudiantes emerge la existencia de apoyos considerables al «golpe de Estado» en sectores de

20] «Los dos manifiestos. Impresión pública», T, 30/01/1908.

21] De los sesenta y seis diputados que firmaron el manifiesto en repudio a la medida presidencial, veintinueve terminaban su mandato en abril del mismo año. Sólo 37 estarán presentes en el nuevo año parlamentario $(T, 30 / 01 / 1908)$.

22] $T, 30 / 01 / 1908$. 
los grupos opositores provinciales, juventudes universitarias, prensa nacional y provincial, dirigentes católicos y las bolsas de comercio de las principales ciudades (CASTRO 2OI2: 223). En la ciudad de Córdoba unos tres mil manifestantes habían recibido con beneplácito la decisión presidencial y la correspondencia que provenía del interior bonaerense también hablaba de la adhesión del comercio y el «elemento independiente», que interpretaba en la decisión presidencial la voluntad de terminar con el roquismo y "garantizar la libertad de sufragio»" ${ }^{23}$. Con todo, una medida excepcional como la del cierre de las sesiones y, fundamentalmente, la decisión presidencial de ocupar militarmente el edificio del Congreso dio lugar a un agitado debate en la prensa y -de manera poco sorpresiva- entre los legisladores una vez que el Parlamento inició un nuevo año de sesiones en mayo. El comienzo de un nuevo período de sesiones también brindó la oportunidad para un intenso intercambio sobre las consecuencias de las elecciones «canónicas» de marzo de 1908, la constitución de una nueva mayoría parlamentaria y las actitudes de la opinión pública hacia el ámbito parlamentario y la influencia electoral del Ejecutivo.

\section{EL «GOLPE DE ESTADO» EN DEBATE: PRENSA Y PARLAMENTARIOS}

Durante la crisis política de comienzos de 1908 publicistas y políticos cercanos a Figueroa Alcorta advirtieron sobre las semejanzas que descubrían entre el caso argentino y la rebelión parlamentaria contra el presidente chileno Balmaceda en I890. El temor de que un grupo de parlamentarios resistiera la política presidencial recurriendo a una rebelión armada iba a sobrevolar los sueltos periodísticos y la correspondencia entre los amigos políticos presidenciales ${ }^{24}$. El diario La Nación, por caso, recuperó parcialmente su antigua retórica republicana que en la segunda mitad del siglo XIx había frecuentemente defendido el derecho a la rebelión de parte de la ciudadanía para enfrentarse a los gobiernos despóticos. En este sentido, la defensa de los ideales republicanos avalaba los levantamientos de parte del pueblo

23] Ramón Cárcano a José Figueroa Alcorta, 25/01/1908, AGN, FJFA, legajo 13; Luis Pedraza a J. Figueroa Alcorta, 07/02/1908, AGN, FJFA, legajo 14.

24] Luis Leguizamón a J. Figueroa Alcorta, 27/01/1908, AGN, FJFA, legajo 13. Rodolfo Rivarola, quien consideraba a la medida inconstitucional, descreía que se estuviera en presencia de un conflicto como el que enfrentó el presidente chileno (RIVAROLA, 1908: 101). 
ante los ejercicios de manipulación electoral y despotismo. En el pasado La Nación ya había asegurado la legitimidad de las revoluciones que expresaban la protesta "varonilmente con las armas en la mano», como Bartolomé Mitre argumentaría en I874 (SABATO, I998: I5I-I52). Y decimos parcialmente porque, pese a que el diario republicano va a rechazar la clausura del Congreso y la influencia oficial en las elecciones de marzo (ZIMMERMANN, I998), insinuará la pertinencia del levantamiento armado sólo para luego manifestar su total improcedencia dada las circunstancias.

Con la apertura del nuevo año parlamentario en medio de una tensa calma, la prensa opositora sugirió otras posibles comparaciones. Para el ahora diario opositor La Nación la crisis política de 1908 hacía recordar a los conflictos que habían tenido lugar en 1890 y en $1895^{25}$. En estas dos últimas coyunturas, el Congreso también había jugado un rol considerable en las tensiones previas y en la resolución final del conflicto. Significativamente, sin embargo, en los acontecimientos de la década de 1890 la combinación de la pérdida de apoyo parlamentario sumado a las crisis ministeriales había conducido a la renuncia de los jefes de Estado. En agosto de I890, la intervención del Congreso había asegurado la aprobación de la renuncia del presidente Miguel Juárez Celman y el ascenso a la primera magistratura del vicepresidente Carlos Pellegrini que asumiría en medio de los debates sobre el alcance de la supresión de las libertades políticas durante el juarismo y de una pesada herencia económica. En ese contexto, el escenario parlamentario había jugado un rol clave en la resolución del entuerto político sobre el telón de fondo de movilizaciones populares en las calles de la ciudad que habían sido interpretadas por la prensa opositora al juarismo como la expresión de la opinión pública, avant-garde de una ansiada regeneración política y moral. En I895, la renuncia de Luis Sáenz Peña a la presidencia como cierre de ese «quinquenio difícil» (GALlo, I980: 237), se daría en el marco de la ausencia de aquella movilización -que había dado los rasgos particulares a la anterior crisis institucional- y con un Congreso que había mantenido una política de constante presión frente a un gobierno que carecía de una base política sólida. En contraste con la crisis política de I890, la indiferencia, más que las protestas en las calles, acompañó la renuncia de Sáenz Peña en enero de I895 (ROJKIND y ROMERo, 20I3).

25] «Crisis política», $L N, 16 / 05 / 1908$. 
En mayo de 1908 La Nación volvió a recordar aquellas coyunturas traumáticas. Para el diario republicano estos ejercicios comparativos dejaban enseñanzas sobre las formas en que la opinión pública había reaccionado frente a las crisis políticas. Para La Nación la resolución de la crisis de i89o se había llevado a cabo de acuerdo a las «exigencias de la opinión pública» que había rechazado el mero cambio de nombres en los gabinetes ministeriales y favorecido por el contrario transformaciones de carácter más profundo. La actitud decidida del Congreso había venido a salvar al gobierno, consolidando el orden constitucional. Se advierte cómo en la interpretación del diario opositor era posible trazar algunas similitudes con aquel momento a partir de la constatación de una inminente crisis ministerial y el cambio de rumbo que se le exigía al ejecutivo nacional. Es significativo que no fuera posible en este caso hacer mención alguna a la actitud de la opinión pública ante los conflictos sobrevenidos entre el escenario parlamentario y el presidente. En este sentido, a la frialdad con que la asamblea parlamentaria había recibido al presidente en mayo de 1908 para la apertura del nuevo período de sesiones se le había agregado la presencia de una concurrencia numerosa de curiosos en las afueras del Congreso que, sin embargo, no habían manifestado un entusiasmo reconocible ante la figura presidencial.

Si una descripción de este estilo de la asistencia a este acto protocolar no sorprende en un diario opositor, no deja de ser significativo que el diario presidencialista Tribuna evitara (a diferencia de los acontecimientos de enero) proponer un retrato de una opinión pública visible que simpatizara con la elección de los nuevos miembros del Congreso. En efecto, para el diario de la tarde las diatribas lanzadas en el Parlamento contra el presidente y los sucesos del 25 de enero no pasaban de ser un ejemplo más de la bancarrota parlamentaria por la que atravesaba el Congreso argentino, resultado de veinte años de vicios electorales. En la visión de Tribuna, ante un espacio parlamentario producto del fraude electoral el pueblo se manifestaba poco preocupado por las incidencias de este pleito entre poderes y esa misma indiferencia anticipaba su opinión sobre los méritos de los parlamentarios. A los ojos de la hoja presidencial el público ya había expresado su simpatía ante el decreto del 25 de enero y la ausencia de manifestaciones en la apertura del año parlamentario solo expresaba el hartazgo de un pueblo hacia el dominio de las máquinas electorales ${ }^{26}$.

26] «El debate de ayer», $T, 08 / 05 / 1908$. 
Por fuera del ámbito de la prensa más cercana a las internas de la elite política, otras expresiones periodísticas como La Vanguardia (en adelante $L V$ ) también habían criticado decididamente el cierre del Congreso y las elecciones de marzo de 1908. Es necesario señalar que, de manera poco sorpresiva, el diario socialista no guardaba simpatía por la conformación del Congreso y el desempeño de sus legisladores. De acuerdo con $L V$, los diputados y senadores no eran más que la expresión de las "pandillas criollas» que defendían los intereses de la «burguesía criolla», siempre dispuestos a sellar buenos acuerdos con los «los rufianes, con los comerciantes, con los capitalistas, con los dueños de casas armadoras y astilleros» ${ }^{27}$. Sin embargo, y en consonancia con la estrategia parlamentaria del partido (MARTínEZ MAZzOLA, 20IO), dedicaba un amplio espacio a relatar los debates legislativos, siguiendo lógicamente de cerca la actuación de Alfredo Palacios (quien había sido electo en 1904) con sus iniciativas de legislación social a lo largo de 1907. Esta estrategia colocaba a los socialistas en una abierta confrontación con el anarquismo que rechazaba aquella participación en el sistema político ${ }^{28}$. Reflejando aquella mirada favorable al parlamentarismo, las plumas socialistas se manifestaron férreas defensoras de la «legalidad» y describieron a la decisión presidencial de clausurar las sesiones del Congreso como un acto «bochornoso. Nos coloca a la altura de Marruecos en sus luchas intestinas por el predominio de uno u otro sultán» ${ }^{29}$.

En efecto, el socialismo criticó fuertemente la ocupación del edificio del Congreso en enero de 1908 y aunque iba a establecer un límite al valor de la «legalidad burguesa» (que se encontraba asociado al interés de la clase trabajadora), no dejaría de señalar que el avance del Poder Ejecutivo sobre el Congreso ponía en riesgo a una institución que podía ser de importancia para la suerte del proletariado. Además, el fuerte rumor que circulaba sobre una posible disolución del Congreso llevaba a los articulistas socialistas a acusar al gobierno de actuar como «anarquistas de arriba» que parecían perseguir la instalación de una «dictadura presidencial $\aleph^{30}$. Por otra parte, la desconfianza de los socialistas hacia la política de reacción institucional de Figueroa Alcorta recibía una nueva confirmación en

27] Mario Bravo, «Nuestros representantes», LV, 18/02/1907; "La impudicia parlamentaria», LV, $17 / 02 / 1907$.

28] «Los anarquistas invocan al Senado!», LV, 25/08/1908.

29] «La oligarquía gobernante. Golpe de estado», LV, 26/01/1908.

30] «La jornada de ayer bajo la dictadura presidencial», LV, 27-28/01/1908; «Pobre constitución», LV, 31/01/1908. 
la forma en que se desarrollaron las elecciones de marzo y las complementarias de octubre en la ciudad de Buenos Aires (el carácter «canónico» de las mismas). Si esta participación en las jornadas electorales volvía a explicitar nuevamente la consideración de la propia fuerza política como un partido que perseguía la modernización de la "política criolla» a través de la intervención en la competencia electoral, la campaña que lanzaría el socialismo en octubre de 1908 en contra del aumento del presupuesto dedicado a armamentos -que se inscribía en el marco de una activa propaganda antibelicista del Partido Socialista (REYES Y BACOLLA, 20I8)- reforzaría también su apuesta por el parlamentarismo ${ }^{31}$.

Incluso dentro de la prensa que, sin estar alineada con el Ejecutivo, había expresado su adhesión general a la política esbozada de reacción institucional, surgían comentarios que censuraban la decisión presidencial. Para el diario $\mathrm{La}$ Prensa, la ocupación del Congreso ordenada por el Ejecutivo nacional había constituido un golpe asestado a la institución de naturaleza «dictatorial». En la visión de uno de los diarios de mayor circulación la clausura representaba una agresión hacia la institución parlamentaria y, en coincidencia con lo que habían sostenido algunos parlamentarios opositores, aquella acción se aproximaba a una «absorción dictatorial del poder público autorizado para votar los impuestos». Aquellos parlamentarios opositores habían denunciado apasionadamente la apatía de una opinión pública que no había rechazado la decisión administrativa de dispersar a las Cámaras ${ }^{32}$. Sin embargo, para La Prensa aquella frialdad del pueblo ante el acto dictatorial expresaba de manera elocuente la actitud de una opinión pública que hacía "público que ese Congreso no le pertenece, porque encarna la usurpación sistemática del sufragio ${ }^{33}$. Ni en los días que siguieron al decreto del 25 de enero ni en el comienzo del nuevo año legislativo se había observado ninguna demostración de carácter popular que evidenciara la existencia de una «comunidad nacional» herida por aquel golpe dictatorial que había afectado a una institución considerada extraña. Desde el punto de vista del diario de los Paz, los responsables de este desorden constitucional debían encontrarse entre los gobernadores que en el pasado habían seguido la dirección de los presidentes electores constituyendo parlamentos que resultaban de la falsificación sistemática del voto.

31] «Contra la paz armada. Solicitud del Senado», LV, 30/10/1908.

32] Discurso del diputado Luis Gonnet, DSCD, 08/05/1908, p. 26.

33] «Frases efectistas. El Congreso y la economía nacional», LP, 10/05/1908. 
Es significativo que, pese a lo inusual de la decisión presidencial de enero, los pasos dados posteriormente obedecieran a una faceta más circunspecta. En lugar de lanzar una campaña sistemática de intervenciones federales el gobierno de Figueroa Alcorta buscó por todos los medios alcanzar acuerdos electorales con los gobiernos provinciales. Esta estrategia desembocó en las llamadas elecciones canónicas de marzo que contribuyeron a «fabricar» una mayoría "presidencial» en la Cámara de Diputados (ramos mexía, [1936] 2015: 197). Como parte de esta estrategia, el presidente no dejó nada librado al azar, sobre todo en lo que se refería a posibles acusaciones de inconstitucionalidad en relación a los acontecimientos de enero. El mensaje presidencial ante el parlamento es evidencia de este nuevo enfoque. La parte política del discurso fue redactada siguiendo los consejos de jurisconsultos (posiblemente Luis V. Varela) a quien Figueroa Alcorta había consultado con el objeto de evitar que aquellas acusaciones prosperaran con la incorporación de los nuevos parlamentarios ${ }^{34}$. Cercano a los círculos políticos bonaerenses, Varela había asesorado a Julio A. Roca durante la intervención federal de 1903 a la provincia de Buenos Aires (posiblemente por su capacidad para dialogar con el ugartismo) y mantenido su participación en la política bonaerense como se desprendía de su asesoramiento al gobernador Irigoyen durante la crisis de 1908. Varela había acercado su consejo al gobernador bonaerense señalando la necesidad de ajustarse a la «sobriedad en la forma y en el fondo» de la parte política de su mensaje ante la legislatura provincial y actuaría en las sombras también diseñando la estrategia de los diputados amigos del presidente en la defensa del decreto del 25 de enero en el parlamento ${ }^{35}$. Aquella «sobriedad» también la había encontrado en la versión final del mensaje del presidente («una exposición seria, serena, digna») que no debería producir reacciones exageradas de aquellos diputados y senadores opositores que, sin embargo, planeaban insistir en las Cámaras con su condena a la ocupación militar del edificio del Congreso ${ }^{36}$. Estos intercambios epistolares y estrechos asesoramientos son evidencia de la importancia asignada por el Ejecutivo nacional a la naturaleza de la relación mantenida con el espacio parlamentario y de los temores de que la clausura de enero (seguido de las elecciones posteriores) pudiera ser interpretada como una práctica de rasgos nítidamente autoritarios.

34] «La parte política del mensaje», $L N, 16 / 5 / 1908$.

35] Luis V. Varela a José Figueroa Alcorta, 05/05/1908 y 08/05/1908, AGN, FJFA, legajo 17.

36] Luis V. Varela a José Figueroa Alcorta, 11/05/1908, AGN, FJFA, legajo 17. 
Las preocupaciones del gobierno en este sentido se dirigían a evitar una crisis de carácter constitucional, si bien cualquier acción desarrollada por los amigos políticos del presidente se demostró insuficiente a la hora de evitar las acusaciones de despotismo ejercidas por la prensa opositora.

El diario La Prensa que se había mostrado como un consistente crítico del roquismo y de las «oligarquías» provinciales dio forma a una aguda impugnación a los argumentos presentados por los senadores opositores luego del cierre del Congreso. Para este diario, el discurso en el recinto del senador que impulsaba la inclusión en el diario de sesiones del manifiesto firmado por los legisladores opositores dejaba ver la poca voluntad de enfrentar al Poder Ejecutivo y la inexistencia de un compromiso firme de «lucha por la reivindicación de las instituciones subvertidas». Esa escasa voluntad de provocar un conflicto institucional se expresaba en los esfuerzos parlamentarios invertidos en demostrar la ausencia de una voluntad obstruccionista contra el gobierno central ${ }^{37}$. De manera poco sorpresiva, Tribuna también le restaba importancia a los discursos opositores en la Cámara de Senadores y coincidía en subrayar la falta de reacción del pueblo ante los atropellos del Poder Ejecutivo sobre el Congreso. En la visión del diario de la tarde, la poca demostración de afecto de la opinión pública hacia los parlamentarios obedecía a la «hartura» de un pueblo que no se demostraba interesado en las incidencias del pleito pero que reconocía haberse liberado del «viejo yugo» de la «triple confradía» de mitristas, ugartistas y roquistas ${ }^{38}$. No deja de ser paradójico, por lo tanto, que el desmantelamiento de la máquina política roquista y la derrota política (momentánea pero decisiva) del ugartismo en la provincia de Buenos Aires allanara el camino a un presidente capaz de desarrollar un programa de reforma política. Como ha señalado Natalio Botana, los legisladores ingresados en la Cámara de Diputados en aquellas elecciones canónicas de marzo de 1908 fueron decisivos en el debate parlamentario que abrió el camino a la sanción de la reforma electoral de I9I2 (воTANA, [1977] 20I2). No deja de ser significativa la relativa popularidad del «golpe de Estado» de enero de 1908 entre la opinión pública porteña y de algunos núcleos urbanos como Córdoba contrastada con la ambigüedad e indiferencia ante los manifiestos emitidos por los parlamentarios opositores en mayo de 1908.

37] $L P, 14 / 5 / 1908$.

38] «El debate de ayer», $T, 08 / 05 / 1908$. 


\section{ALGUNAS CONSIDERACIONES FINALES}

En principio podríamos argumentar, en sintonía con la interpretación de Marcela Ternavasio y Paula Alonso (20II) para el período inmediato anterior de finales del siglo XIX, que aún a comienzos del siglo xx y hasta la sanción de la ley Sáenz Peña sería la cuestión del sufragio (acompañada por el grado de centralización política) las que primarían en la agenda de los debates políticos, dejando relativamente a un lado (o subordinada) la cuestión de la división de poderes. En un sentido, puede advertirse que un hecho «dictatorial» como el cierre del Congreso recibe una condena relativamente limitada tanto de los amigos políticos del presidente como (de manera más inesperada) de los opositores políticos que evitaban iniciar el poco explorado y acaso peligroso camino del juicio político. Significativamente, sería un argumento similar al que el diario La Prensa había utilizado en 1908 (el Congreso como expresión de una suma de oligarquías provinciales que habrían producido, por medios fraudulentos, representantes con una legitimidad viciada) el que haría propio posteriormente Hipólito Yrigoyen durante su primer período al frente de la presidencia, en su conflictiva relación con el Congreso (MUSTAPIC, I984). Sin embargo, también es importante señalar que aun cuando la ocupación militar del edificio del Congreso no tuvo mayores consecuencias legales dio lugar a un intenso debate en la prensa y en el ámbito parlamentario con la apertura de las sesiones en mayo. El ambiguo discurso de Figueroa Alcorta en esa ocasión también advierte sobre la clara conciencia de los riesgos posibles que una disolución del Congreso (como algunos de sus amigos políticos lo invitaban a realizar) podía conllevar.

La prensa nacional y de la ciudad de Buenos Aires constituía un foro de discusión que amplificaba la repercusión de las discusiones parlamentarias y no dejaría de expresar la magnitud del impacto institucional generado por el «golpe de Estado» de 1908. Era innegable que, a pesar de la prédica constante de la prensa acerca de la influencia persistente de los gobiernos electores y la influencia de los Ejecutivos sobre la vida política nacional y provincial, el Congreso mantenía su rol en el andamiaje institucional y así era percibido por una diversidad de actores de la sociedad civil quienes aceptaban la necesidad de ejercer presión sobre el mismo a fin de obtener decisiones favorables. A la luz de esas preocupaciones y de la centralidad que adquiría la figura presidencial en el entramado institucional argentino (de acuerdo con los lineamientos trazados desde el modelo constitucional de I853I860), las relaciones dificultosas entre el Congreso y el Poder Ejecutivo durante 
la presidencia de Figueroa Alcorta y particularmente el momento culminante del conflicto (el «golpe de Estado» de 1908) colocan bajo una perspectiva diferente a la cuestión de la representatividad de los parlamentarios, las relaciones entre los poderes y el lugar del Congreso en el ordenamiento político argentino. Por otra parte, si bien la importancia del Poder Ejecutivo no podía ser subestimada, la institución parlamentaria había retenido un importante rol en tiempos de crisis política como había tenido lugar en 1890 o I895. La importancia atribuida a la publicidad de los procedimientos legislativos se reflejaba en la difusión de los manuales legislativos, la preocupación por garantizar el principio de la publicidad de los actos legislativos e incluso en los extensos y enojosos debates sobre la construcción del edificio del Congreso. En este sentido, y a pesar de las críticas constantes dirigidas hacia los legisladores en relación al ausentismo parlamentario, las tácticas de obstruccionismo o su legitimidad de origen, el Congreso se mantenía como una de las instituciones hacia la cual dirigían sus estrategias un conjunto amplio de actores sociales y políticos, desde asociaciones religiosas y sindicatos a clubes y partidos políticos. Aún en tiempos de conflicto extremo como durante el año 1908 (y aún a pesar del escepticismo con el que observaban un conjunto de actores la independencia legislativa del Congreso), su lugar estratégico central en el tratamiento y aprobación de las leyes aseguraba, de manera poco sorpresiva, la elaboración de campañas de propaganda y entrega de petitorios que tenían a los parlamentarios como destinatarios (CASTRO, 20I4). En todo caso, si este aspecto no aparecería como excesivamente sorpresivo, correspondería revisar, al menos parcialmente, las reconstrucciones historiográficas del periodo que colocan un excesivo peso e importancia en las prácticas del presidencialismo centralizador sobre el comportamiento del Parlamento en el ocaso de la «república oligárquica». 


\section{Referencias bibliográficas}

ALONSO, PAULA (2000): Entre la revolución y las urnas. Los orígenes de la Unión Cívica Radical y la política argentina en los años '90, Buenos Aires, Sudamericana/ Universidad de San Andrés. ALONSO, PAULA (2010): Jardines secretos, legitimaciones públicas. El Partido Autonomista Nacional y la política argentina a fines del sig/o $X I X$, Buenos Aires, Edhasa.

BOTANA, NATALIO (2012): El orden conservador. La política argentina entre 1880 y 1916, Buenos Aires, Edhasa.

BRAGONI, BEATRIZY MÍGUEZ, EDUARDO (2010): Un nuevo orden político. Provincias y Estado nacional 1852-1880, Buenos Aires, Biblos.

CANTÓN, DARÍ0 (1966): El Parlamento argentino en épocas de cambio: 1890, 1916 y 1946, Buenos Aires, Editorial del Instituto.

CASTRO, MARTíN 0. (2009): «Nacionalismo, cuestión religiosa y secularización política en la Argentina a comienzos del siglo XX, 1900-1914», en: Bicentenario. Revista de Historia de Chile y América, vol. 8, n² 2, pp. 5-40.

CASTRO, MARTín 0. (2012): El ocaso de la república oligárquica. Poder, política y reforma electoral, 1898-1912, Buenos Aires, Edhasa.

CASTRO, MARTín. 0. (2014): «Estanislao Zeballos: sensibilidad diletante, nacionalismo y estado, 1906-1912», en: Anuario del Centro de Estudios Históricos «Profesor Carlos S. A. Segreti», n 14, pp. 183-201.

CASTRO, MARTín. 0. (2017): «Sites of power, instruments of public intervention: the Palace of Congress and the construction of federal power in Argentina, 1880-1916», en: Parliaments, Estates and Representations, vol. 37, $\mathrm{n}^{\circ} 2$, pp. 206-219. CUCCHI, LAURA Y ROMERO, ANA (2017): «Tensions between Congress and the Executive in nineteenthcentury Argentina: federal intervention and separation of powers», en: Parliaments, Estates and Representation, vol. 37, n² 2, pp. 193-205. GALLO, EZEQUIEL (1980): «Un quinquenio difícil: las presidencias de Carlos Pellegrini y Luis Sáenz Peña (1890-1895)», en: G. Ferrari y E. Gallo, La Argentina del Ochenta al Centenario. Buenos Aires, Sudamericana.

GERCHUNOFF, PABLO, ROCCHI, FERNANDO Y ROSSI, GASTÓN (2008): Desorden y progreso. Las crisis económicas argentinas 1870-1905, Buenos Aires, Edhasa.

IHALAINEN, PASI; ILIE, CORNELIA Y PLONEN, KARI (2018): Parliament and Parliamentarism. A comparative history of a European concept, Oxford, Berghahn. MACKINNON, MOIRA (2017): «¿Máquina de legislar o foro deliberativo? El Congreso en Chile y Argentina a la hora de la legislación laboral», en: Desarrol/o Económico, vol. 57, n 221, pp. 63-90.

MARTÍNEZ MAZZOLA, RICARDO (2010): «Socialismo y populismo, los comienzos de una relación conflictiva. La mirada del socialismo argentino sobre la Unión Cívica Radical (1890-1930)», en: Anuario del Centro de Estudios Históricos «Prof. Carlos S.A. Segreti», $\mathrm{n}^{\circ} 10$.

MÍGUEZ, EDUARDO (2012): «Gestación, auge y crisis del orden político oligárquico en la Argentina. Balance de la historiografía reciente», en: Polhis, no 9, pp. 38-68.

MOLINELLI, N. GUILLERMO (1991): Presidentes y congresos en Argentina: mitos y realidades, Buenos Aires, Grupo Editor Latinoamericano.

MORENO LUZÓN, JAVIER (2015): De las urnas al hemiciclo. Elecciones y parlamentarismo en la Península Ibérica (1875-1926), Madrid, Marcial Pons. MUSTAPIC, ANA M. (1984): «Conflictos institucionales durante el primer gobierno radical, 1916-1922», en: Desarrollo Económico, vol. 24, n 93, pp. 85-108. 
NEGRETTO, GABRIEL Y AGUILAR-RIVERA, JOSÉ ANTONIO (2000): «Rethinking the Legacy of the Liberal State in Latin America: The cases of Argentina (1853-1916) and Mexico (1857-1910)», en: Journal of Latin American Studies, vol. 32, $\mathrm{n}^{\circ}$ 2, pp. 361-397.

POSADA CARBÓ, EDUARDO (2017): «Congresses versus Caudillos: the untold history of democracy in Latin America, with special emphasis on New Granada (Colombia), 1830-1860», en: Parliaments, Estates and Representation, vol. 37, $\mathrm{n}^{\circ}$ 2, pp. 119-129.

RAGAZZONI, DAVID Y URBINATI, NADIA (2018): «Theories of Representative Government and Parlamentarism in Italy from the 1840s to the 1920s", en: Ihalainen, Pasi, Ilie Cornelia y Kari Palonen (eds.), Parliament and Parliamentarism. A comparative history of a European concept, Oxford, Berghahn, pp. 243-260. RAMOS MEXÍA, EZEQUIEL (2015): Mis memorias: 1853-1935, Buenos Aires, Claridad.

REGLAMENTO DE LA CÁMARA DE SENADORES DE LA NACIÓN (1907): Buenos Aires, El Comercio.

REGLAMENTO DE LA CÁMARA DE DIPUTADOS DE LA NACIÓN ARGENTINA (1909): Buenos Aires, EI Comercio.

REYES, FRANCISCO Y BACOLLA, NATACHA (2018): «LOS socialistas argentinos ante el conflicto argentinochileno. Formas y sentidos del antimilitarismo en los orígenes del Partido Socialista en Argentina (1894-1902)», en: Iberoamericana, XVIII, nº 68, pp. 201-226.

RIVAROLA, RODOLFO (1908): «La política argentina después de la muerte de Mitre», en R. Rivarola, Del régimen federativo al unitario, Buenos Aires, Peuser.

ROJKIND, INÉS (2006): «Prensa, manifestaciones y oposición política. La protesta contra la unifica- ción de la deuda en julio de 1901», en: Estudios Sociales, n 31, pp. 137-162.

ROJKIND, INÉS Y ROMERO, ANA (2013): «Renuncias presidenciales, opinión pública y legitimidad en el quinquenio difícil (1890-1895)», en PolHis, $n^{\circ}$ 11, pp. 94-105.

ROLDÁN, DARÍO (COMP.) (2006): Crear la democracia. La Revista Argentina de Ciencias Políticas y el debate en torno de la República Verdadera, Buenos Aires, Fondo de Cultura Económica.

SOMMARIVA, LUIS (1931): Historia de las intervenciones federales en las provincias, Buenos Aires, El Ateneo, vol. II.

SABATO, HILDA (1998): La política en las calles. Entre el voto y la movilización. Buenos Aires, 1862-1880, Buenos Aires, Sudamericana.

SABATO, HILDA (2008): Buenos Aires en armas. La revolución de 1880, Buenos Aires, S XXI.

SABATO, HILDA (2014): «Los desafíos de la república. Notas sobre la política en la Argentina pos Caseros", en: Estudios Sociales, Universidad Nacional del Litoral, n 46, pp. 77-117.

SCHMIDT, CLAUDIA (2012): Palacios sin reyes. Arquitectura pública para la "capital permanente». Buenos Aires, 1880-1890, Rosario, Prohistoria. TERNAVASIO, MARCELA Y ALONSO PAULA (2011): «Liberalismo y ensayos políticos en el siglo XIX argentino», en Iván Jaksic y Eduardo Posada Carbó (eds.), Liberalismo y poder. Latinoamérica en el sig/o XIX, Santiago de Chile, Fondo de Cultura Económica, pp. 279-319.

ZIMMERMANN, EDUARD0 (1998): «La prensa y la oposición política en la Argentina de comienzos de siglo: el caso de <La Nación y el Partido Republicano», en: Estudios Sociales, Universidad Nacional del Litoral, $n^{\circ} 15$, pp. 45-70. 